\title{
Opioid and Adenosine Peripheral Antinociception Are Subject to Tolerance and Withdrawal
}

\author{
K. O. Aley,,$^{3,4}$ P. G. Green, ${ }^{3,4}$ and J. D. Levine ${ }^{1,2,3,4}$ \\ Departments of ${ }^{1}$ Anatomy, ${ }^{2}$ Medicine, and ${ }^{3}$ Oral and Maxillofacial Surgery and ${ }^{4}$ Division of Neuroscience, University \\ of California, San Francisco, California 94143
}

The selective $\mu$-opioid agonist, D-Ala ${ }^{2}, \mathrm{~N}-\mathrm{Me}-\mathrm{Phe}^{4}, \mathrm{Gly}^{5}$-olenkephalin (DAMGO), or the selective $A_{1}$-adenosine agonist $\mathrm{N}^{6}$-cyclopentyladenosine (CPA), when coinjected intradermally with prostaglandin $E_{2}\left(P G E_{2}\right)$, dose-dependently inhibited $\mathrm{PGE}_{2}$-induced mechanical hyperalgesia in the rat hindpaw, as determined by the Randall-Selitto paw-withdrawal test. Repeated (hourly $\times 3$ ) intradermal injections of DAMGO or CPA produced tolerance to the antinociceptive effect of a fourth injection $1 \mathrm{hr}$ later. Furthermore, repeated (hourly $\times 3$ ) intradermal injections of DAMGO produced cross-tolerance to the antinociceptive effect of CPA, and repeated (hourly $\times 3$ ) intradermal injection of CPA produced cross-tolerance to the antinociceptive effect of DAMGO. The demonstration of the bidirectional cross-tolerance between the peripheral antinociceptive effects of DAMGO and CPA supports the hypothesis that both these agents produce antinociception by acting on the same cell, presumably the primary afferent nociceptor, and that the development of tolerance involves changes downstream to activation of $\mu$-opioid and $A_{1}$-adenosine receptors.

The opioid antagonist naloxone, which had no effect on paw-withdrawal threshold in normal paws, produced withdrawal hyperalgesia in DAMGO-tolerant paws. Furthermore, naloxone elicited a cross-withdrawal hyperalgesia response in CPA-tolerant paws. Similarly, the $A_{1}$-adenosine antagonist 1,3-dipropyl-8-(2-amino-4-chlorophenyl)-xanthine (PACPX), which had no effect on paw-withdrawal threshold in normal paws, elicited a withdrawal hyperalgesia response in CPA-tolerant paws and cross-withdrawal hyperalgesia response in DAMGO-tolerant paws. These crossdependence and cross-withdrawal responses suggest that the development of dependence to $\mu$-opioid and $A_{1}$-adenosine agonists involves changes in the same second messenger system downstream to both $\mu$-opioid and $A_{1}$-adenosine receptor activation.

[Key words: $A_{1}$-adenosine, pain, peripheral opioid tolerance, physical dependence, $\mu$-opioid receptor]

The systemic administration of opioids produces potent antinociception in animals, and analgesia in humans, by actions both in the dorsal horn of the spinal cord and at supraspinal sites

Received June 23, 1995; revised Aug. 9, 1995; accepted Aug. 14, 1995.

We thank Allan Basbaum, Philip Heller, David Reichling, E. Leong Way, and Kimherly Tanner for many helpful discussions during the course of this work. This work was funded by NIH DE08973.

Correspondence should be addressed to Jon D. Levine, M.D., Ph.D., Department of Medicine, Box 0452, University of California, San Francisco, CA 94143.

Copyright (C) 1995 Society for Neuroscience $0270-6474 / 95 / 158031-08 \$ 05.00 / 0$
(Mayer and Price, 1976; Duggan, 1979; Fields and Basbaum, 1978). Clinical and animal studies have shown that opioids also cxcrt antinociccptive cffects at peripheral sites in inflamed tissue and inhibit $\mathrm{PGE}_{2}$-induced hyperalgesia (Ferreira and Nakamura, 1979; Smith et al., 1982; Stein et al., 1988, 1989, 1991; Levine and Taiwo, 1989; Kayser et al., 1990; Parsons and Herz, 1990; Taiwo and Levine, 1990; Wheeler-Aceto and Cowan, 1991; Junien and Wettstein, 1992; Moiniche et al., 1993). There is, at present, a significant interest in the peripheral use of opioids for analgesia, since such use should avoid side-effects (e.g, respiratory depression) that develop to the central action of systemically administered opioids, which often limit their therapeutic use. However, it is not known if peripherally acting opioids would produce tolerance to their analgesic effects which, like for central action, also significantly limits usefulness.

Recent experiments have provided some understanding of mechanisms active in opioid tolerance. Most evidence indicates that tolerance to opioid effects in the CNS is due to a functional uncoupling between the opioid receptor and its second messenger, an inhibitory guanosine triphosphate-binding protein (Gprotein), $G_{i}$ (Collin and Cesselin, 1991), through which opioid agonists act to produce many of their effects (Costa et al., 1988) including antinociception (Levine and Taiwo, 1989). For example, while chronic opioid exposure does not in general alter opioid binding to its receptor, opioid inhibition of adenylyl cyclase activity is decreased after chronic exposure (Polastron et al., 1990). In addition, in other in vitro systems chronic administration of morphine results in a loss of the ability of guanine nucleotides to modulate the affinity of the $\mu$-opioid receptor for its ligands, associated with a downregulation of high affinity sites (Puttfarcken et al., 1988; Werling et al., 1989).

$\mathrm{A}_{1}$-Adenosine agonists [such as $\mathrm{N}^{6}$-cyclopentyladenosine (CPA)], like $\mu$-opioids, are able to act in the peripher y to inhibit prostaglandin $\mathrm{E}_{2}\left(\mathrm{PGE}_{2}\right)$-induced hyperalgesia (Taiwo and Levine, 1990). $\mathrm{A}_{1}$-Adenosine receptors are also coupled to an inhibitory $G$-protein, and $A_{1}$-receptor activation also results in inhibition of adenylyl cyclase activity and decreased levels of cAMP (Cooper et al., 1980). Tolerance at the $A_{1}$-adenosine receptor occurs following repeated administration of $A_{1}$-adenosine agonists (Casati et al., 1994; Tsuchida et al., 1994). However, $\mathrm{A}_{1}$-adenosine receptor-mediated tolerance has not yet been reported with regard to its antinociceptive effects.

In the present study we determined if tolerance develops with regard to the peripheral antinociception produced by a $\mu$-opioid or an $\mathrm{A}_{1}$-adenosine agonist. The ability of these agonists to induce cross-tolerance and the ability of opioid and adenosine antagonists to precipitate a withdrawal hyperalgesia was also investigated. 
Table 1. Abbreviations of agents used

\begin{tabular}{lll} 
Abbreviation & Agent & Action \\
\hline PGE $_{2}$ or $\mathrm{E}_{2}$ & ${\text { Prostaglandin } \mathrm{E}_{2}}$ & Hyperalgesic inflammatory mediator \\
$\mathrm{DAMGO}$ or $\mathrm{D}$ & $\left\lceil\mathrm{D}-\mathrm{Ala}^{2}, \mathrm{~N}-\mathrm{Me}_{-} \mathrm{Phe}^{4}, \mathrm{gly}^{5}\right.$-ol] enkephalin & $\mu_{-}$-Opioid receptor agonist \\
$\mathrm{MMI}$ & Morphine methyl iodide & Quaternary sait of morphine \\
$\mathrm{N}$ & $\mathrm{Naloxone}$ & Opioid receptor antagonist \\
$\mathrm{CPA}$ & $\mathrm{N}^{6}$-Cyclopentyl-adenosine & $\mathrm{A}_{1}$-adenosine receptor agonist \\
PACPX & 1,3 -Dipropyl-8-(2-amino-4-chlorphenyl)-xanthine & $\mathrm{A}_{1}$-adenosine receptor antagonist
\end{tabular}

\section{Materials and Methods}

Animals. Experiments were performed on male Sprague-Dawley rats (250-300 gm; Bantin and Kingman, Fremont, CA). Animals were housed in groups of two or three, under a $12 \mathrm{hr}$ light/12 hr dark cycle. Food and water were available ad libitum. All testing was done between 10:00 and 16:00 hr. Experiments were carried out under approval of the Institutional Animal Care Committee of the University of California, San Francisco.

Behavioral testing. The nociceptive flexion reflex was quantified with a Basile Analgesymeter (Stoelting, Chicago, IL), which applies a linearly increasing mechanical force to the dorsum of the rat's hindpaw. Rats were trained in the test procedure during the week prior to the experiments, a procedure which produces a stable baseline threshold measurement and enhances the ability to detect the action of hyperalgesic agents (Taiwo et al., 1989). On the day of the experiment, baseline threshold was determined. The mean baseline mechanical nociceptive paw-withdrawal threshold in these experiments was $110.4 \pm 0.4 \mathrm{gm}, n$ $=340$ (mean paw-withdrawal threshold \pm SEM). Mechanical threshold was redetermined at different time points $(15,20$, and $25 \mathrm{~min})$ after treatments. The mean of these three readings was considered to be the paw-withdrawal threshold following drug administration and this value was used to calculate the percentage change from the baseline threshold.

Drug administration. The drugs used in this study were prostaglandin $\mathrm{E}_{2} \quad \mathrm{PGE}_{2}$, hyperalgesic inflammatory mediator), D-Ala ${ }^{2}, \mathrm{~N}-\mathrm{Me}-$ $\mathrm{Phe}^{4}$, Glys-ol-enkephalin (DAMGO; $\mu$-opioid receptor agonist), $\mathrm{N}^{6}$-cyclopentyl-adenosine (CPA, $A_{1}$-adenosine receptor agonist), nialoxone $\mathrm{HCl}$ (opioid receptor antagonist), all from Sigma, St. Louis, MO; 1,3dipropyl-8-(2-amino-4-chlorophenyl)-xanthine (PACPX, $A_{1}$-adenosine receptor antagonist) from Research Biochemicals Inc., Natick, MA; and morphine methyliodide (quaternary salt of morphine, which exhibits opioid agonist properties similar to its parent compound, but does not cross the blood brain barrier), a generous gift from Dr. Ivy Carroll, NIDA, Research Triangle Institute. The selection of the drug doses employed in this study was hased on dose-response curves determined during this study (DAMGO and CPA) or previously by our laboratory (Levine and Taiwo, 1989; Taiwo and Levine, 1990; Aley et al., 1995). The stock solution of PGE $(1 \mu \mathrm{g} / 2.5 \mu 1)$ was prepared in $10 \%$ ethanol and further dilutions made in saline. DAMGO, CPA, naloxone, and morphine methyliodide were dissolved in saline. PACPX was dissolved in dimelhyl sulfoxide (DMSO, $8 \mathrm{mg} / \mathrm{ml}$ ) and further dilutions made in saline. Maximum final concentration of ethanol injected was $<1 \%$, and the maximum final concentration of DMSO injected was $<5 \%$. All drugs were injected intradermally (i.d.) in a volume of $2.5 \mu \mathrm{l} / \mathrm{paw}$. In addition, morphine methyliodide was also injected subcutaneously. When drug combinations were used, they were administered sequentially as indicated from the same syringe. Antagonists were always injected first. Abbreviations for the drugs administered in this study and their actions, are located in Table 1.

Experimental protocol. Rats used in this study were divided into different groups; details of drug treatments for each group is given in Table 2.

Statistical analysis. Data are presented as mean \pm SEM of six or more paws in each of the experimental groups. Statistical significance was determined by analysis of variance (ANOVA) followed by Scheffe's post-hoc test; $p<0.05$ was considered statistically significant.

\section{Results}

Inhibition of $P G E_{2}$ hyperalgesia by DAMGO or CPA Intradermal injection of $\mathrm{PGE}_{2}(100 \mathrm{ng})$ into the hairy skin of the hindpaw of the rat significantly decreased paw-withdrawal threshold ( $p<0.05$; Fig. 1). Both DAMGO (Fig. 1A) and CPA (Fig. $1 B$ ) dose-dependently inhibited $\mathrm{PGE}_{2}$-inhibited hyperalgesia (both $p<0.05$ ); that is, both produced marked antinociception.

\section{Tolerance to peripheral DAMGO and CPA antinociception}

Two or more hourly injections of either DAMGO $(1 \mu \mathrm{g})$ (Fig. $2 A$ ) or CPA (1 $\mu \mathrm{g}$ ) (Fig. $2 B$ ) produced a complete tolerance to their antinociceptive effects $(D \times 2, D+E 2$ compared to $E 2$, and $C P A x 2, C P A+E 2$ compared to $E 2$, both $p>0.05$ ). To ensure tolerance for all animals tested, DAMGO or CPA were administered hourly for $3 \mathrm{hr}$ in subsequent experiments. When DAMGO $(1 \mu \mathrm{g})$ and naloxone $(1 \mu \mathrm{g})$ were coinjected hourly for $3 \mathrm{hr}$ and at the fourth hour DAMGO plus $\mathrm{PGE}_{2}$ was injected, DAM$\mathrm{GO}$ antinociception was not significantly different from that produced by DAMGO in opioid-naive rats $((N+D) \times 3, D+E 2 \mathrm{com}-$ pared to $D \times 3, D+E 2, p>0.05$; Fig. $2 A)$; that is, coinjection of DAMGO with naloxone prevented the development of DAMGO tolerance. Naloxone appears to be acting locally at the site of injection, to inhibit DAMGO antinociception, since DAMGO antinociception is not altered in the paw contralateral to that receiving naloxone (unpublished data). When CPA $(1 \mu \mathrm{g})$ and PACPX $(1 \mu \mathrm{g})$ were coinjected hourly for $3 \mathrm{hr}$ and at the fourth hour CPA plus $\mathrm{PGE}_{2}$ was injecled, CPA antinociception was not significantly different from that produced by CPA in CPA-naive rats $((P A C P X+C P A) \times 3, C P A+E 2$ compared to $C P A \times 3, C P A+E 2, p$ $>0.05$; Fig. $2 B$ ); that is, coinjection of PACPX with CPA prevented the development of CPA tolerance.

\section{Cross-tolerance between DAMGO and CPA antinociception}

Three hourly injections of DAMGO $(1 \mu \mathrm{g})$ prior to an injection of CPA plus $\mathrm{PGE}_{2}$, at the fourth hour, significantly blocked CPA antinociception $(D \times 3, C P A+E 2$ compared to $C P A+E 2,(p<$ 0.05 ; Fig. 3 ); that is, cross-tolerance developed between DAMGO and CPA. Similarly, three hourly injections of CPA $(1 \mu \mathrm{g})$ prior to an injection of DAMGO plus $\mathrm{PGE}_{2}$ significantly blocked DAMGO antinociception tested at the fourth hour $(C P A \times 3, D+E 2$ compared to $D+E 2, p<0.05$ ); that is, cross-tolerance developed between CPA and DAMGO.

\section{Effect of naloxone on DAMGO-and CPA-induced tolerance}

The opioid antagonist naloxone $(1 \mu \mathrm{g})$ blocked DAMGO antinociception $(N+D+E 2$ compared to $D+E 2, p<0.05$; Fig. 4), but not $C P A$ antinociception $(N+C P A+E 2$ compared to $C P A+E 2, p>0.05$; Fig. 4); that is, DAMGO but not CPA is acting through an opioid receptor to induce antinociception. Three hourly injections of DAMGO $(1 \mu \mathrm{g})$ had no significant effect on basal paw-withdrawal threshold (Dx3 compared with saline vehicle $V x 3, p>0 ; 05$; Fig. 4). The opioid antagonist naloxone $(1 \mu \mathrm{g})$ also did not have a significant effect on the 


\begin{tabular}{|c|c|c|c|}
\hline Group & $N$ & Treatment & Doser $(s)$ \\
\hline $1 \mathrm{a}$ & 16 & $\mathrm{PGE}_{2}$ & $100 \mathrm{ng}$ \\
\hline b & 6 & $\mathrm{DAMGO}+\mathrm{PGE}_{2}$ & $1 \mathrm{ng} / 100 \mathrm{ng}$ \\
\hline $\mathrm{c}$ & 6 & $\mathrm{DAMGO}+\mathrm{PGE}_{2}$ & $10 \mathrm{ng} / 100 \mathrm{ng}$ \\
\hline $\mathrm{d}$ & 6 & $\mathrm{DAMGO}+\mathrm{PGE}_{2}$ & $100 \mathrm{ng} / 100 \mathrm{ng}$ \\
\hline $\mathrm{e}$ & 16 & $\mathrm{DAMGO}+\mathrm{PGE}_{2}$ & $1 \mu \mathrm{g} / 100 \mathrm{ng}$ \\
\hline $2 \mathrm{a}$ & 6 & $\mathrm{CPA}+\mathrm{PGE}_{2}$ & $1 \mathrm{ng} / 100 \mathrm{ng}$ \\
\hline $\mathrm{b}$ & 6 & $\mathrm{CPA}+\mathrm{PGE}_{2}$ & $10 \mathrm{ng} / 100 \mathrm{ng}$ \\
\hline $\mathrm{c}$ & 6 & $\mathrm{CPA}+\mathrm{PGE}_{2}$ & $100 \mathrm{ng} / 100 \mathrm{ng}$ \\
\hline $\mathrm{d}$ & 12 & $\mathrm{CPA} \mid \mathrm{PGE}_{2}$ & $1 \mu \mathrm{g} / 100 \mathrm{ng}$ \\
\hline $3 a$ & 6 & DAMGO $\times 1,2$ nd hr DAMGO $+\mathrm{PGE}_{2}$ & $1 \mu \mathrm{g} \times 1,1 \mu \mathrm{g} / 100 \mathrm{ng}$ \\
\hline $\mathrm{b}$ & 6 & DAMGO hourly $\times 2$, 3rd hr DAMGO $+\mathrm{PGE}_{2}$ & $1 \mu \mathrm{g} \times 2,1 \mu \mathrm{g} / 100 \mathrm{ng}$ \\
\hline $\mathrm{c}$ & 6 & DAMGO hourly $\times 3,4$ th hr DAMGO $+\mathrm{PGE}_{2}$ & $1 \mu \mathrm{g} \times 3,1 \mu \mathrm{g} / 100 \mathrm{ng}$ \\
\hline $\mathrm{d}$ & 6 & DAMGO hourly $\times 4,5$ th hr DAMGO $+\mathrm{PGE}_{2}$ & $1 \mu \mathrm{g} \times 4,1 \mu \mathrm{g} / 100 \mathrm{ng}$ \\
\hline $4 \mathrm{a}$ & 6 & $\mathrm{CPA} \times 1,2 \mathrm{nd}$ hr $\mathrm{CPA}+\mathrm{PGE}_{2}$ & $1 \mu \mathrm{g} \times 1,1 \mu \mathrm{g} / 100 \mathrm{ng}$ \\
\hline b & 6 & $\mathrm{CPA}$ hourly $\times 2,3$ rd hr $\mathrm{CPA}+\mathrm{PGE}_{2}$ & $1 \mu \mathrm{g} \times 2,1 \mu \mathrm{g} / 100 \mathrm{ng}$ \\
\hline $\mathrm{c}$ & 6 & CPA hourly $\times 3,4$ th hr $\mathrm{CPA}+\mathrm{PGE}_{2}$ & $1 \mu \mathrm{g} \times 3,1 \mu \mathrm{g} / 100 \mathrm{ng}$ \\
\hline d & 6 & CPA hourly $\times 4,5$ th hr $\mathrm{CPA}+\mathrm{PGE}_{2}$ & $1 \mu \mathrm{g} \times 4,1 \mu \mathrm{g} / 100 \mathrm{ng}$ \\
\hline 5 a & 10 & DAMGO hourly $\times 3,4$ th hr CPA + PGE $_{2}$ & $1 \mu \mathrm{g} \times 3,1 \mu \mathrm{g} / 100 \mathrm{ng}$ \\
\hline b & 10 & CPA hourly $\times 3,4$ th hr DAMGO $+\mathrm{PGE}_{2}$ & $1 \mu \mathrm{g} \times 3,1 \mu \mathrm{g} / 100 \mathrm{ng}$ \\
\hline 6 a & 6 & Naloxone + DAMGO $+\mathrm{PGE}_{2}$ (co-injection) & $1 \mu \mathrm{g} / 1 \mu \mathrm{g} / 100 \mathrm{ng}$ \\
\hline b & 6 & Naloxone $+\mathrm{CPA}+\mathrm{PGE}_{2}$ (co-injection) & $1 \mu \mathrm{g} / 1 \mu \mathrm{g} / 100 \mathrm{ng}$ \\
\hline $\mathrm{c}$ & 14 & DAMGO hourly $\times 3$ & $1 \mu \mathrm{g} \times 3$ \\
\hline d & 6 & Vehicle hourly $\times 3$ & $2.5 \mu \mathrm{l} \times 3$ \\
\hline $\mathrm{e}$ & 6 & Vehicle $\times 3$, 4th hr naloxone & $2.5 \mu \mathrm{l} \times 3,1 \mu \mathrm{g}$ \\
\hline f & 6 & Naloxone + DAMGO $\times 3,4$ th hr DAMGO $+\mathrm{PGE}_{2}$ & $1 \mu \mathrm{g} / 1 \mu \mathrm{g} \times 3,1 \mu \mathrm{g} / 100 \mathrm{ng}$ \\
\hline $7 \mathrm{a}$ & 18 & DAMGO hourly $\times 3,4$ th hr naloxone & $1 \mu \mathrm{g} \times 3,1 \mu \mathrm{g}$ \\
\hline b & 6 & CPA hourly $\times 3,4$ th hr naloxone & $1 \mu \mathrm{g} \times 3,1 \mu \mathrm{g}$ \\
\hline $\mathrm{c}$ & 6 & DAMGO hourly $\times 3,4$ th hr DAMGO + naloxone & $1 \mu \mathrm{g} \times 3,1 \mu \mathrm{g} / 1 \mu \mathrm{g}$ \\
\hline $\mathrm{d}$ & 12 & DAMGO hourly $\times 3,4$ th hr CPA + naloxone & $1 \mu \mathrm{g} \times 3,1 \mu \mathrm{g} / 1 \mu \mathrm{g}$ \\
\hline $\mathrm{e}$ & 6 & CPA hourly $\times 3$, 4th hr DAMGO + naloxone & $1 \mu \mathrm{g} \times 3,1 \mu \mathrm{g} / 1 \mu \mathrm{g}$ \\
\hline f & 8 & CPA hourly $\times 3,4$ th hr CPA + naloxone & $1 \mu \mathrm{g} \times 3,1 \mu \mathrm{g} / 1 \mu \mathrm{g}$ \\
\hline $8 \mathrm{a}$ & 6 & $\mathrm{PACPX}+\mathrm{CPA}+\mathrm{PGE}_{2}$ (co-injection) & $1 \mu \mathrm{g} / 1 \mu \mathrm{g} / 100 \mathrm{ng}$ \\
\hline b & 6 & PACPX + DAMGO + PGE $_{2}$ (co-injection) & $1 \mu \mathrm{g} / 1 \mu \mathrm{g} / 100 \mathrm{ng}$ \\
\hline$c$ & 10 & CPA hourly $\times 3$ & $1 \mu \mathrm{g} \times 3$ \\
\hline $\mathrm{d}$ & 6 & Vehicle hourly $\times 3$, 4th hr PACPX & $2.5 \mu \mathrm{l} \times 3,1 \mu \mathrm{g}$ \\
\hline e & 6 & PACPX + CPA hourly $\times 3,4$ th hr CPA + PGE $_{2}$ & $1 \mu \mathrm{g} / 1 \mu \mathrm{g} \times 3,1 \mu \mathrm{g} / 100 \mathrm{ng}$ \\
\hline 9 a & 8 & CPA hourly $\times 3$, PACPX & $1 \mu \mathrm{g} \times 3,1 \mu \mathrm{g}$ \\
\hline b & 8 & DAMGO hourly $\times 3$, 4th hr PACPX & $1 \mu \mathrm{g} \times 3,1 \mu \mathrm{g}$ \\
\hline $\mathrm{c}$ & 6 & CPA hourly $\times 3$, 4th hr CPA + PACPX & $1 \mu \mathrm{g} \times 3,1 \mu \mathrm{g} / 1 \mu \mathrm{g}$ \\
\hline $\mathrm{d}$ & 6 & CPA hourly $\times 3,4$ th hr DMAGO + PACPX & $1 \mu \mathrm{g} \times 3,1 \mu \mathrm{g} / 1 \mu \mathrm{g}$ \\
\hline $\mathrm{e}$ & 6 & DAMGO hourly $\times 3,4$ th hr DAMGO + PACPX & $1 \mu \mathrm{g} \times 3,1 \mu \mathrm{g} / 1 \mu \mathrm{g}$ \\
\hline $\mathrm{f}$ & 6 & DAMGO hourly $\times 3,4$ th hr CPA + PACPX & $1 \mu \mathrm{g} \times 3,1 \mu \mathrm{g} / 1 \mu \mathrm{g}$ \\
\hline $10 \mathrm{a}$ & 6 & Morphine methyl iodide $+\mathrm{PGE}_{2}$ & $10 \mu \mathrm{g} / 100 \mathrm{ng}$ \\
\hline b & 6 & Morphine methyl iodide $+\mathrm{PGE}_{2}$ & $100 \mu \mathrm{g} / 100 \mathrm{ng}$ \\
\hline $\mathrm{c}$ & 6 & Morphine methyl iodide $(\mathrm{SC})+\mathrm{PGE}_{2}$ & $100 \mu \mathrm{g}(\mathrm{SC}) / 100 \mathrm{ng}$ \\
\hline
\end{tabular}

Abbreviations: $\mathrm{PGE}_{2}$, Prostaglandin $\mathrm{E}_{2}$ (EP receptor agonist); DAMGO, D-Ala ${ }^{2}, \mathrm{~N}-\mathrm{Me}_{-}-\mathrm{Phe}^{4}, \mathrm{gly}{ }^{5}$-ol ( $\mu$-opioid receptor agonist); CPA, $\mathrm{N}^{6}$-cyclopentyl adenosine $\left(\mathrm{A}_{1}-\right.$ adenosine agonist); PACPX, 1,3-dipropyl-8-(2-amino-4-chlorphenyl)-xanthine (Al-adenosine antagonist); SC, subcutaneous (in the neck).

paw-withdrawal threshold of rats treated with three hourly injections of saline vehicle ( $V x 3, N$ compared with $V x 3, p>0.05$; Fig. 4).

In rats treated with three hourly injections of DAMGO $(1 \mu \mathrm{g})$, administration of naloxone at the fourth hour produced a significant decrease in paw-withdrawal threshold (i.e., hyperalgesia) (Dx3,N compared to $D \times 3, p<0.05$; Fig. 5). Similarly, in rats treated with three hourly injections of CPA $(1 \mu \mathrm{g})$, administration of naloxone at the fourth hour produced a significant decrease in paw-withdrawal threshold ( $C P A x 3, N$ compared with
CPAx3, $p<0.05$; Fig. 5). In the DAMGO and CPA treated rats, the paw-withdrawal threshold at the fourth hour, prior to the administration of naloxone, was not significantly different from the basal paw-withdrawal threshold (Figs. 5, 7). Naloxone-induced hyperalgesia in a DAMGO-tolerant paw could be inhibited by coadministration of DAMGO with naloxone at the fourth hour ( $D \times 3, D+N$ compared to $D \times 3, N, p<0,05$; Fig. 5). Coadministration of CPA with naloxone did not block naloxone-induced hyperalgesia in DAMGO-tolerant paws $(D \times 3, C P A+N$ compared with DAMGOx3,N,p>0.05; Fig. 5). In CPA-tolerant 
A

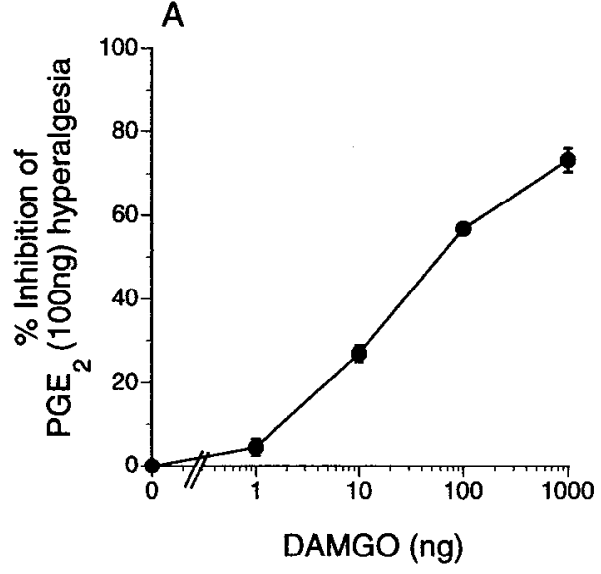

B

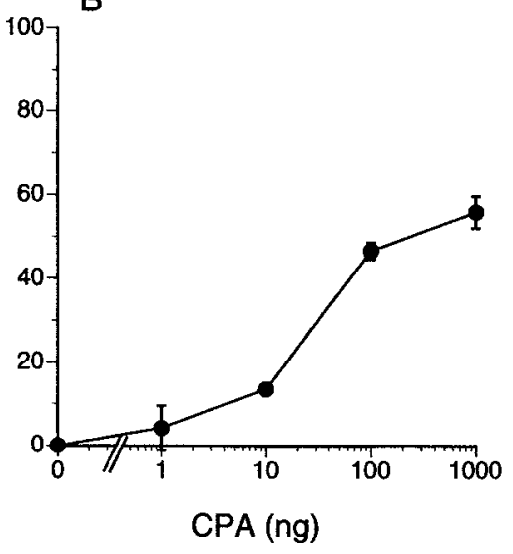

Figure 1. Dose-dependent inhibition of $\mathrm{PGE}_{2}$-induced hyperalgesia by DAMGO and CPA. Effect of $\mathrm{PGE}_{2}$ (100 ng, $n=16$ ) on paw-withdrawal thresholds and its modification by different doses of: $A$, DAMGO $(n=6)$, or $B$, CPA $(n=6)$. In this and subsequent figures where no error bars seen, they are contained within the symbols. paws coadministration of CPA with naloxone resulted in crosswithdrawal hyperalgesia ( $C P A x 3, C P A+N$ compared to $C P A \times 3$, $p<0.05$ ), although it was slightly decreased $(p<0.05) \mathrm{com}-$ pared to administration of naloxone alone (CPAx3,CPA+N compared with $C P A \times 3, N, p<0.05$; Fig. 5). However, in CPA-tolerant paws DAMGO did block naloxone-induced withdrawal

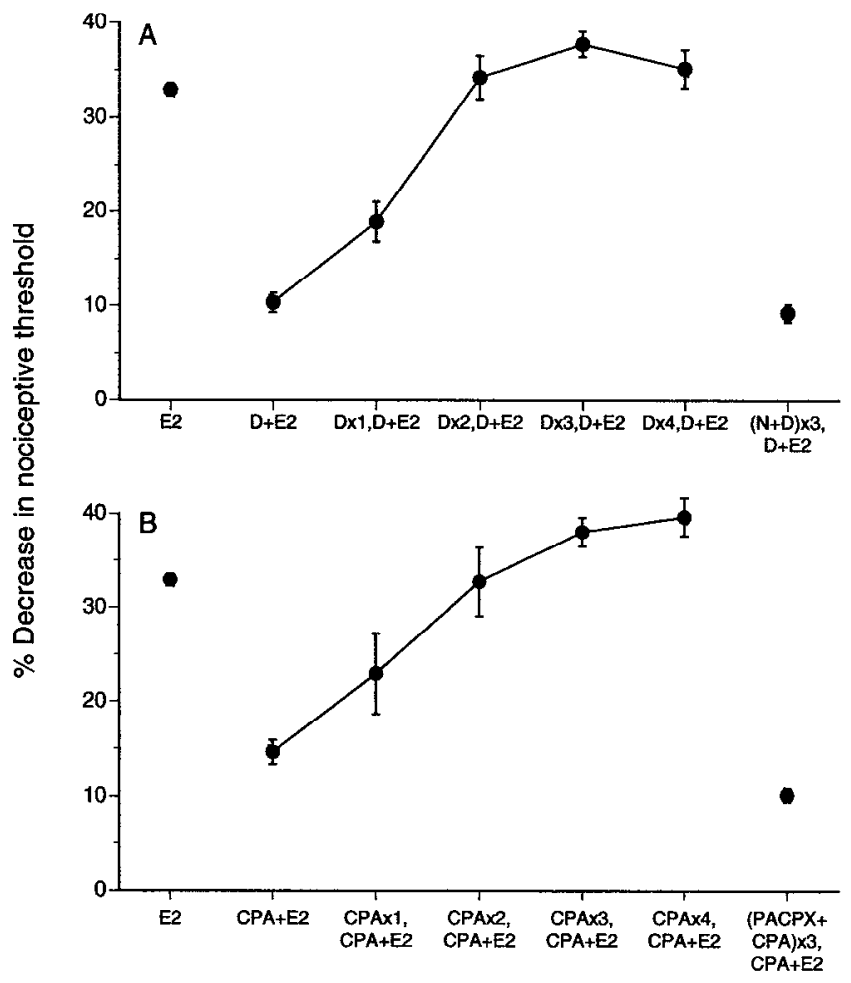

Figure 2. Time course for the development of tolerance to DAMGOand CPA-induced antinociception and the blockade of the development of tolerance by coadministration of specific receptor antagonists. A, Erfect of different number of preceding hourly doses of DAMGO $(D)(1$ $\mu \mathrm{g})$ on DAMGO inhibition of $\mathrm{PGE}_{2}$ hyperalgesia $(D \times 2, D+E 2=\mathrm{DAM}-$ GO hourly $\times 2$, then DAMGO plus $\mathrm{PGE}_{2}$ at the next hour, and similarly for 3 and $4 \mathrm{hr}$ ). Naloxone plus DAMGO hourly $\times 3$ and at the fourth hour DAMGO plus $\mathrm{PGE}_{2}(N+D x 3, D+E 2, n=6) . B$, Effect of different number of preceding hourly doses of CPA $(C P A)(1 \mu \mathrm{g})$ on CPA inhibition of $\mathrm{PGE}_{2}$ hyperalgesia $(C P A x 2, C P A+E 2=$ CPA hourly $\times 2$, then CPA plus $\mathrm{PGF}_{2}$ at the next hour, and similarly for 3 and $4 \mathrm{hr}$ ). PACPX plus CPA hourly $\times 3$ and at the fourth hour CPA plus $\mathrm{PGE}_{2}$ $(P A C P X+C P A x 3, C P A+E 2, n=6)$. hyperalgesia (CPAx3,D+N compared to $C P A x 3, N, p<0.05$; Fig. 5).

\section{Effects of PACPX on CPA- and DAMGO-induced tolerance}

The $\mathrm{A}_{1}$-adenosine antagonist PACPX $(1 \mu \mathrm{g})$ blocked CPA antinociception $(P A C P X+C P A+E 2$ compared to $C P A+E 2, p<$ 0.05; Fig. 6), but not DAMGO antinociception $(P A C P X+D+E 2$ compared to $D+E 2, p>0.05$; Fig. 6); that is, CPA but not DAMGO is acting at the $A_{1}$-adenosine receptor. Three injections of CPA $(1 \mu \mathrm{g})$, one every hour, had no significant effect on paw-withdrawal threshold (CPAx3 compared to $V x 3, p>0 ; 05$; Fig. 6). PACPX (1 $\mu \mathrm{g})$ also did not have a significant effect on the paw-withdrawal threshold of rats treated with three hourly injections of saline vehicle ( $V x 3, P A C P X$ compared to $V x 3, p>$ 0.05 ; Fig. 6).

In rats treated with three hourly injections of CPA $(1 \mu \mathrm{g})$, administration of PACPX at the fourth hour produced a significant decrease in paw-withdrawal threshold (i.e., hyperalgesia) (CPAx3,PACPX compared to $C P A x 3, p<0.05$, Figs. 7). Similarly, after three hourly injections of DAMGO $(1 \mu \mathrm{g})$, administration of PACPX at the fourth hour produced a significant decrease in paw-withdrawal threshold (i.e., hyperalgesia) (Dx3,PACPX, compared to $D \times 3, p<0.05$; Fig. 7). The pawwithdrawal threshold in the CPA- and DAMGO-treated rats, at

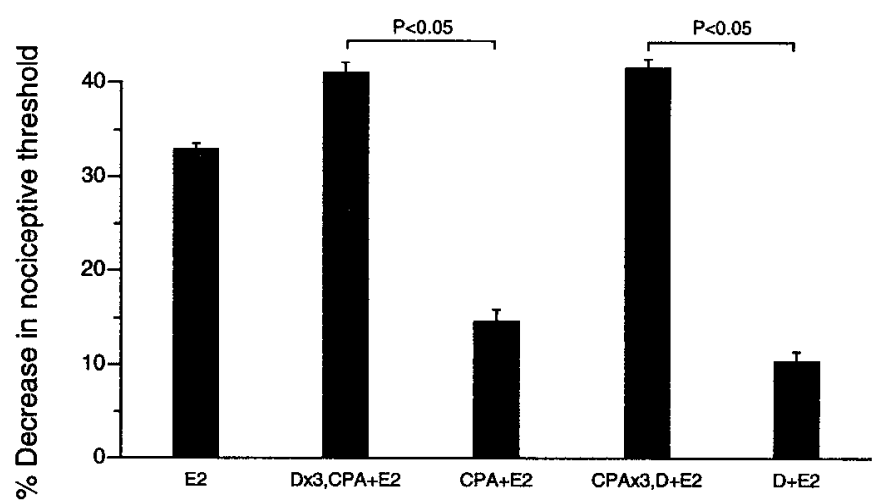

Figure 3. Bidirectional cross-tolerance develops between DAMGOand CPA-induced antinociception. Effect of $\mathrm{PGE}_{2}(E 2, n=16)$; DAMGO hourly $\times 3$ and at the fourth hour CPA plus $\mathrm{PGE}_{2}(D \times 3, C P A+E 2$, $n=10)$ compared to DAMGO and $\mathrm{PGE}_{2}(D+E 2, n=16)$; and CPA hourly $\times 3$ and at the fourth hour DAMGO plus $\mathrm{PGE}_{2}(C P A x 3, D+E 2$, $n=10)$ compared to CPA plus $\mathrm{PGE}_{2}(C P A+E 2, n=10)$ on mechanical paw-withdrawal threshold in the rat. 


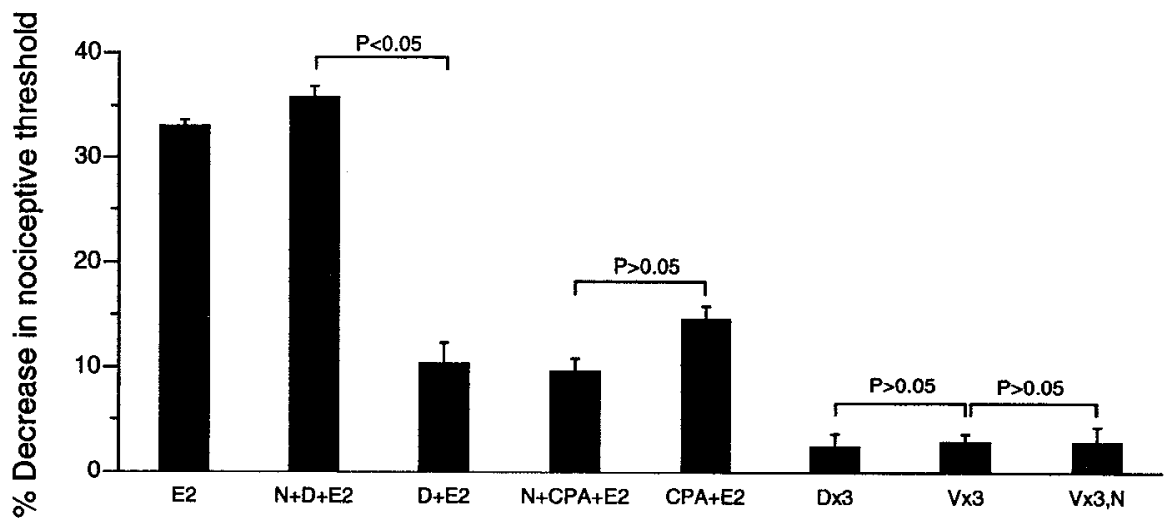

Figure 4. Naloxone blocks DAMGObut not CPA-induced antinociception. Effect of $\mathrm{PGE}_{2}(E 2, n=16)$, DAMGO and $\mathrm{PGE}_{2}(D+E 2, n=16)$, naloxone, DAMGO and $\mathrm{PGE}_{2}(N+D+E 2, n=$ 6), $\mathrm{CPA}$ and $\mathrm{PGE}_{2}(C P A+E 2, n=12)$, naloxone, $\mathrm{CPA}$ and $\mathrm{PGE}_{2}(N+C P A+E 2$, $n=6)$, DAMGO hourly $\times 3$ (D) $3, n$ $=14)$, Saline $(2.5 \mu \mathrm{l} / \mathrm{paw})$ hourly $\times 3$ $(S \times 3, n=6)$, saline $(2.5 \mu \mathrm{l} /$ paw $)$ hourly $\times 3$ and at the fourth hour naloxone $(V \times 3, N, n=6)$.

the fourth hour prior to the administration of PACPX, was not statistically significant from the basal paw-withdrawal threshold (Figs. 5, 7). PACPX-induced withdrawal hyperalgesia could be inhibited by coadministration of CPA with PACPX at the fourth hour (CPAx3,CPA+PACPX compared to Dx3,PACPX, $p<$ 0.05 ; Fig. 7). However, coadministration of DAMGO with PACPX did not block PACPX-induced withdrawal hyperalgesia in CPA-tolerant paws (CPAx3,D+PACPX compared to $C P A x 3, P A C P X, p>0.05)$. In DAMGO-tolerant paws coadministration of DAMGO with PACPX did not block PACPX-induced withdrawal hyperalgesia $(D \times 3, D+P A C P X$, compared to $D \times 3, p<0.05$; Fig. 7). However, in DAMGO-tolerant paws CPA did block PACPX-induced withdrawal hyperalgesia (Dx3,CPA + PACPX compared to Dx3,PACPX, $p<0.05$; Fig. 7).

\section{Effect of morphine methyliodide on $P G E_{2}$-hyperalgesia}

To confirm that the antinociceptive effect of intradermally administered opioid was due to its peripheral action, the effect of a quaternary salt of morphine on $\mathrm{PGE}_{2}$-induced hyperalgesia was evaluated. Morphine methyliodide (MMI) (10 and $100 \mu \mathrm{g})$ was antinociceptive (E2 compared with $M M I(10 \mu g)+E 2$ and $E 2$ compared to $M M I(100 \mu g)+E 2$, both $p<0.05$, Fig. 8). However, subcutaneous (in the neck) injection of morphine methyliodide failed to inhibit $\mathrm{PGE}_{2}$-induced hyperalgesia $(100 \mu \mathrm{g}$, $M M I(100 \mu g, S C)+E 2$ compared to $E 2)(p>0.05)$.

\section{Discussion}

In this study, we found that tolerance develops to the peripheral antinociceptive effects of DAMGO and CPA after repeated administration of these agents in the hindpaw of the rat. Since the development of tolerance is blocked by coadministration of naloxone (but not PACPX) with DAMGO or of PACPX with CPA (but not DAMGO), we suggest that DAMGO is acting at an opioid receptor (presumably $\mu$ ) and CPA is acting at an $\mathrm{A}_{1}$ adenosine receptor to produce tolerance. In a previous study, repeated subcutaneous (i.e., systemic) administration of morphine failed to produce tolerance to the antinociceptive activity of intraplantar (i.e., local peripheral) morphine administration (Ferreira et al., 1984). The lack of observed tolerance to peripheral morphine in that study may be due to the difference in the route of drug administration used to induce tolerance compared to our study.

Following injection into the hindpaw, DAMGO and CPA probably exert their antinociceptive effects locally, since the doses administered are too low to have an effect in the CNS (Taiwo and Levine, 1990). This hypothesis is supported by the observation that the quaternary compound morphine methyliodide, which does not as readily enter the CNS, produced antinociception following intradermal administration into the hindpaw, but not when the same dose was administered systemically (subcutaneously at a distant site).

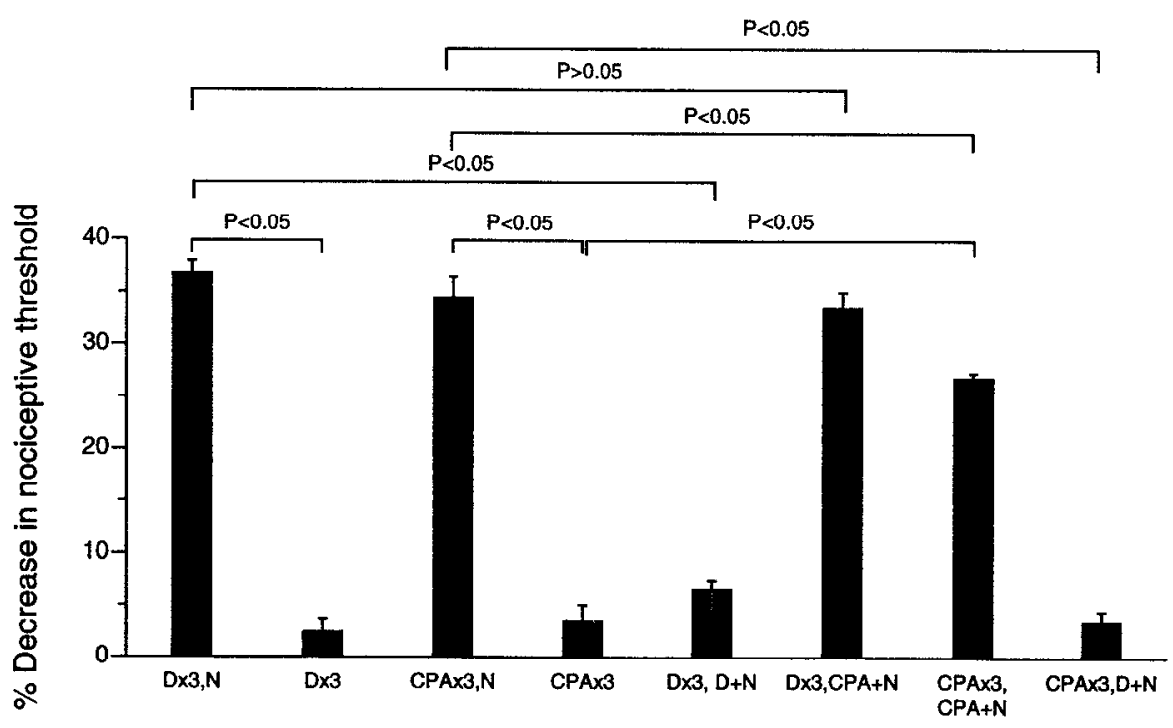

Figure 5. Naloxone induces withdrawal hyperalgesia in DAMGO- and CPA-tolerant paws. Effect of DAMGO hourly $\times 3$ and at the fourth hour nal oxone ( $D x 3, N, n=18)$, CPA hourly $\times$ 3 and at the fourth hour naloxone $(C P A x 3, N, n-6)$, DAMGO hourly $x$ 3 and at the fourth hour DAMGO plus naloxone $(D \times 3, D+N, n=6)$, DAMGO hourly $\times 3$ and at the fourth hour CPA plus naloxone ( $D x 3, C P A+N, n=12)$, CPA hourly $\times 3$ and at the fourth hour DAMGO plus naloxone ( $C P A \times 3, D+N$, $n=6$ ), and CPA hourly $\times 3$ and at the fourth hour CPA plus naloxone $(C P A \times 3, C P A+N, n=8)$ on mechanical paw-withdrawal threshold in the rat. 
Figure 6. PACPX blocks CPA- but not DAMGO-induced antinociception. Effect of $\mathrm{PGE}_{2}(E 2, n=16)$, CPA and $\mathrm{PGE}_{2}(C P A+E 2, n=12)$, PACPX $\mathrm{CPA}$ and $\mathrm{PGE}_{2}(P A C P X+C P A+E 2, n$ =6), DAMGO and $\mathrm{PGE}_{2}(D+E 2, n=$ 16), PACPX, DAMGO and $\mathrm{PGE}_{2}$ $(P A C P X+D+E 2, n=6)$, CPA hourly $\times 3(C P A x 3, n=10)$, saline $(2.5 \mu \mathrm{l})$ hourly $\times 3(S \times 3, n=6)$, saline $(2.5 \mu 1 /$ paw) hourly $\times 3$ and at the fourth hour PACPX (Vx3,PACPX, $n=6)$.

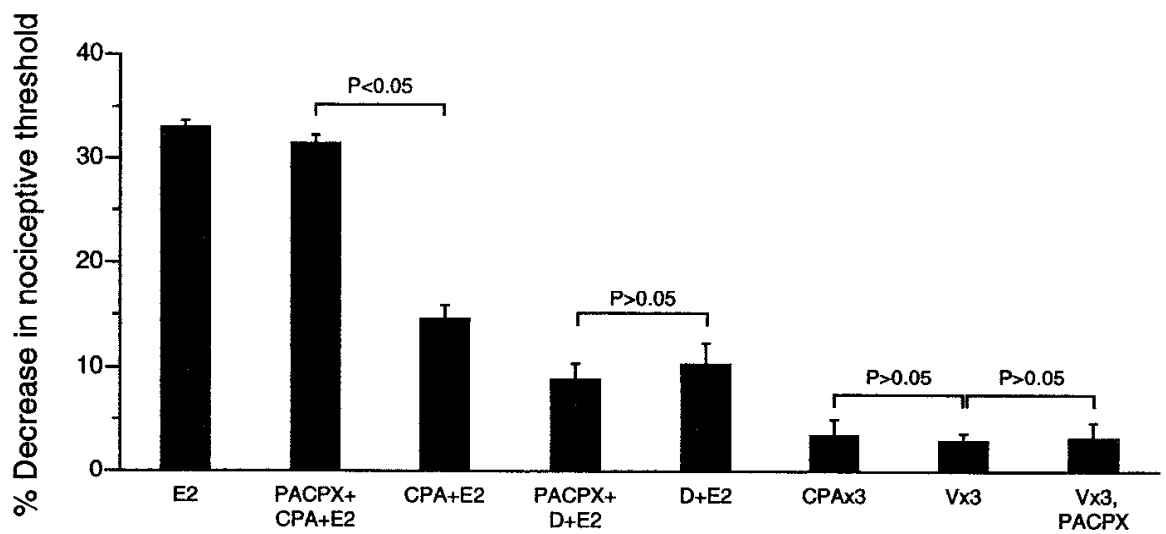

Our data also indicate that there is cross-tolerance between DAMGO and CPA since in the DAMGO-tolerant paw CPA was not antinociceptive, and in the CPA-tolerant paw DAMGO was not antinociceptive. The bidirectional cross-tolerance between DAMGO and CPA suggests that opioid and $A_{1}$-adenosine receptors on the same cell, possibly the primary afferent nociceptor, and are coupled to a common second messenger system that participates in the development of tolerance. There is now considerable evidence that cAMP mediates the hyperalgesic effects of $\mathrm{PGE}_{2}$ (Ferreira and Nakamura, 1979; Taiwo and Levine, 1991; Hingtgen et al., 1995) as well as a sensitization of primary afferent neurons (Pitchford and Levine, 1991; Vasko et al., 1994; Wang et al., 1995). For example, $\mathrm{PGE}_{2}$ raises immunoreactive cAMP levels in sensory neuron cultures, which results in an enhanced release of primary afferent neurotransmitter peptides (evoked by bradykinin or capsaicin) (Hingtgen et al., 1995). Incrcascd cAMP levels will also produce an increase in the phosphorylation of intracellular proteins, including ion channels, thereby increasing neuronal excitability. In fact, several studies have demonstrated that both cAMP and prostaglandins enhance sensory neuron excitation produced by bradykinin or capsaicin (Martin et al., 1987; Dray et al., 1992; Ouseph et al., 1995). Therefore, it is of note that it has been shown that both opioids and $A_{1}$-adenosine antinociceptive agents act on receptors coupled to G-proteins (Ferreira, 1981; Taiwo and Levine, 1991; Ingram and Williams, 1994), which decrease cAMP levels (VanCaulker et al., 1979; Hamprecht and VanCaulker, 1985). These results suggest that primary afferent induced hyperalgesia and antinociception involve modulation of a common second messenger pathway (Hingtgen et al., 1995).

An alternative explanation for the observed cross-tolerance is that repeated DAMGO administration could release endogenous adenosine (to act at and tolerize $\mathrm{A}_{1}$-receptors). This alternative explanation is unlikely for two reasons. First, while endogenous opioids can be released in peripheral tissues, this only occurs in the setting of inflammation (Stein et al., 1990), and opioids, such as DAMGO, are anti-inflammatory in peripheral tissues. Second, since P $\Lambda$ CPX did not affect DAMGO antinociception (suggesting endogenous adenosine is not involved) and naloxone did not affect CPA antinociception (suggesting that endogenous opioids are not involved), it is unlikely that cross-tolerance between DAMGO and CPA is due to release of endogenous ligands.

Tolerance to the effects of opioids is commonly associated with the development of dependence on the opioid, most often evident by the presence of an abstinence-induced or an antagonist-precipitated withdrawal (Way, 1993). For example, after development of tolerance to the antinociceptive effect of morphine, hyperalgesia might result if the opioid is discontinued or if naloxone were administered. We found that both in DAMGOand CPA-tolerant paws, a withdrawal response is induced by the selective opioid and $\mathrm{A}_{1}$-adenosine antagonists respectively, and also that a cross-withdrawal response is observed (Figs. 5, 7). Antagonist-induced withdrawal is thought to result from displacement of the agonist from its receptor binding sites. How ever, the observation of cross-withdrawal suggests that dependence in this model is not maintained solely by receptor occu-
Figure 7. PACPX induces withdrawal hyperalgesia in CPA- and DAMGOtolerant paws. Effect of CPA hourly $X$ 3 and at the fourth hour PACPX (CPAx3,PACPX, $n=8$ ), DAMGO hourly $\times 3$ and at the fourth hour PACPX (D $3, P A C P X, n=8)$, CPA hourly $\times 3$ and at the fourth hour CPA plus PACPX (CPAx3,CPA I PACPX, $n$ $=6$ ), CPA hourly $\times 3$ and at the fourth hour DAMGO plus PACPX $(C P A x 3, D+P A C P X, n=6)$, DAMGO hourly $\times 3$ and at the fourth hour DAMGO plus PACPX $(D \times 3, D+P A C P X$, $n=6$ ), DAMGO hourly $\times 3$ and at the fourth hour CPA plus PACPX (Dx3,CPA+PACPX, $n=6)$ on mechanical paw-withdrawal threshold in the rat.

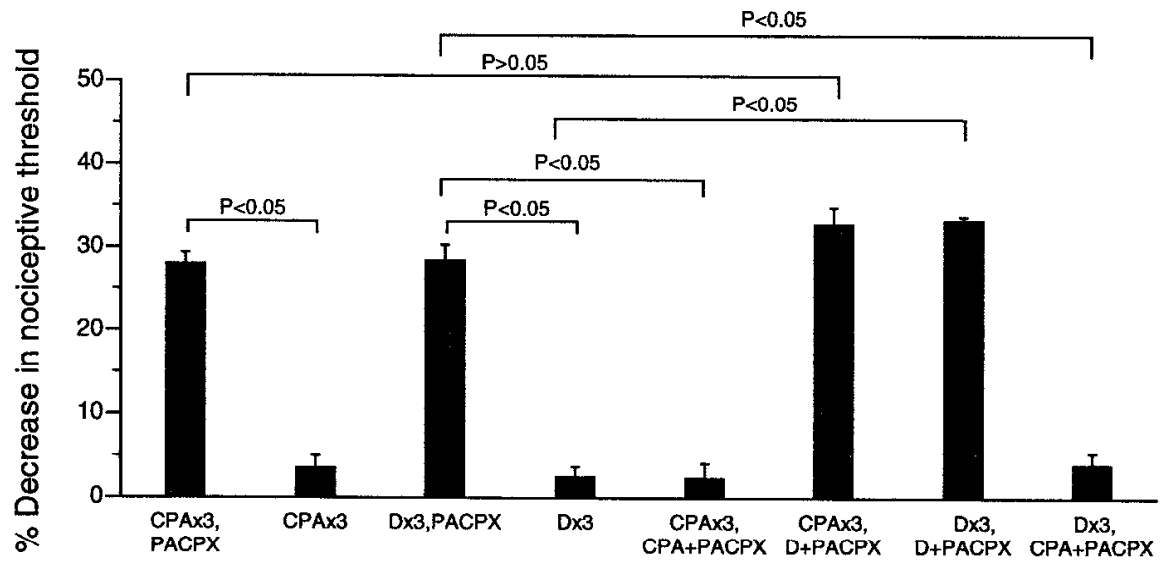




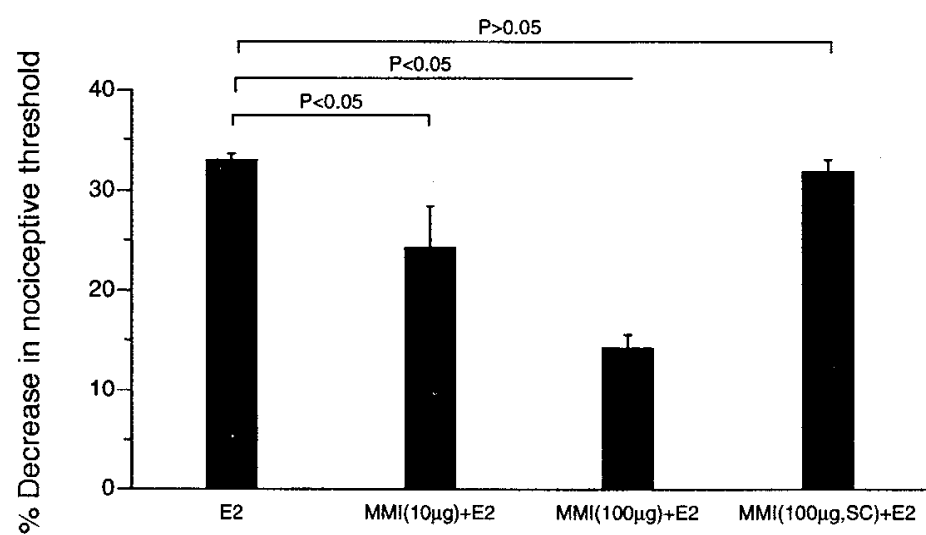

Figure 8. Quaternary morphine inhibits $\mathrm{PGE}_{2}$-induced hyperalgesia. Effect of $\mathrm{PGE}_{2}(E 2, n=16)$, morphine methyliodide $(10 \mu \mathrm{g})$ plus $\mathrm{PGE}_{2}$ $(M M I(10 \mu g)+E 2, n=6)$, morphine methyliodide $(100 \mu \mathrm{g})$ plus $\mathrm{PGE}_{2}$ $(M M I(100 \mu g)+E 2, n=6)$, and morphine methyliodide $100 \mu \mathrm{g}$ s.c. plus PGE $(M M I(I 00 \mu g, S C)+E 2, n=6)$ on mechanical paw-withdrawal threshold in the rat.

pancy. A recent model of opioid dependence suggested by Wang and colleagues (1994) is of interest in this regard. These workers hypothesize that $\mu$-opioid agonists produce dependence by inducing a spontaneously active phosphorylated state of the $\mu$-opioid receptor at which naloxone can act as an inverse agonist. Thus, cross-tolerance may be a result of phosphorylation of both the $\mathrm{A}_{1}$-adenosine as well as the $\mu$-opioid receptor following chronic exposure to either CPA or DAMGO.

DAMGO failed to block PACPX-induced withdrawal hyperalgesia in DAMGO-tolerant paws (Fig. 7). Similarly, CPA administered with naloxone in CPA-tolerant paws resulted in a marked naloxone-induced cross-withdrawal (Fig. 5); however, there was a small, but statistically significant, reduction compared to naloxone alone. This small difference may be due to an incomplete tolerance for CPA agonism produced following three hourly injections.

In conclusion, we report that both $\mu$-opioid and $\mathrm{A}_{1}$-adenosine agonists produce tolerance to their peripheral antinociceptive effects on repeated administration. Furthermore, we suggest that both $\mu$-opioid and $A_{1}$-adenosine receptors share a common second messenger pathway in the induction of tolerance since there is cross-tolerance between agonists acting at these two receptors. Finally the observation of naloxone- and PACPX-induced withdrawal in both opioid- and CPA-tolerant paws, supports the hypothesis of the development of a cross-dependence as well as a cross-tolerance for the peripheral antinociceptive effects of $\mu$-opioid and $A_{1}$-adenosine agonists. The failure of the opioid agonist to block the withdrawal effect of the $A_{1}$-adenosine antagonist and the failure of the adenosine agonist to block the withdrawal effect of opioid antagonist, irrespective of the agonist $\left(\mu\right.$ or $A_{1}$ ) used to induce tolerance, suggests that it is not necessary for an agonist to occupy a receptor for an antagonist to be able to precipitate withdrawal and thus that there must be changes in the action of the antagonist at that receptor (e.g., phosphorylation of the receptor so that the antagonist can now act as an inverse agonist; Wang et al., 1994). This suggests that the changes associated with dependence may involve cellular mechanisms distinct from those underlying tolerance. Further studies are in progress to investigate the specific second messenger pathways in the primary afferent underlying these phenomena.

\section{References}

Aley KO, Khasar SG, Levine JD (1995) Multiple second messenger systems act sequentially to mediate rolipram-induced prolongation of prostaglandin $\mathrm{E}_{2}$-induced mechanical hyperalgesia in the rat. Neuroscience 64:769-776.

Casati C, Monopoli A, Dionisotti S, Zocchi C, Bonizzoni E, Ongini E (1994) Repeated administration of selective adenosine $A_{1}$ and $A_{2}$ receptor agonist in the spontaneously hypertensive rat: tolerance develops to $A_{1}$-mediated hemodynamic effects. J Pharmacol Exp Ther 268:1506-1511.

Collin E, Cesselin F (1991) Neurobiological mechanisms of opioid tolerance and dependence. Clin Neuropharmacol 14:465-488.

Cooper DMF, Londos C, Rodbell R (1980) Adenosine receptor mediated inhibition of rat cerebral cortical adenylate cyclase by a GTPdependent process. Mol Pharmacol 18:598-601.

Costa T, Klinz FJ, Vachon L, Herz A (1988) Opioid receptors are coupled tightly to $G$ proteins but loosely to adenylate cyclase in NG108-15 cell membranes. Mol Pharmacol 34:744-754.

Cox BM, Ginsburg M, Osman OH (1968) Acute tolerance to narcotic analgesic drugs in rats. Br J Pharmacol 33:245-256.

Dray A, Patel IA, Perkins MN, Rueff A (1992) Bradykinin-induced activation of nociceptors: receptor and mechanistic studies on the neonatal rat spinal cord-tail preparation in vitro. Br J Pharmacol 107: $1129-1134$.

Duggan AW (1979) Morphine and enkephalins at the spinal cord. Adv Pain Res Ther 3:449-458.

Ebersolt C, Premont J, Prochiantz A, Perez M, Bockaert J (1983) Inhibition of brain adenylate adenylate cyclase by $A_{1}$ adenosine receptors: pharmacological characteristics and locations. Brain Res 267: 123-129.

Ferreira SH (1981) Local control of inflammatory pain. Agents Actions 11:636-638.

Ferreira SH, Nakamura M (1979) Prostaglandin hyperalgesia, a cAMP/ $\mathrm{Ca}^{2+}$-dependent process. Prostaglandins 18:179 190.

Ferreira SH, Lorenzetti BB, Rae GA (1984) Is methylnalorphinium the prototype of an ideal peripheral analgesic? Eur J Pharmacol 99:2329.

Fields HL, Basbaum AI (1978) Brainstem control of spinal pain-transmission neurons. Annu Rev Physiol 4:451-462.

Hamprecht B, VanCaulker P (1985) Nomenclature of adenosine receptors. Trends Pharmacol Sci 6:151-154.

Harada H, Ueda H, katada T, Ui M, Satoh M (1990) Phosphorylated $\mu$-opioid receptor purified from rat brain lacks functional coupling with $G_{i}$, a GTP-binding protein in reconstituted lipid vesicles. Neurosci I ett 113:47-49

Hingtgen C, Waite K, Vasko M (1995) Prostaglandins facilitate peptide release from rat sensory neurons by activating the adenosine $3^{\prime}, 5^{\prime}$ cyclic monophosphate transduction cascade. J Neuroscience 15: 5411-5419.

Ingram SL, Williams JT (1994) Opioid inhibition of Ih via adenylyl cyclase. Neuron 13:179-186.

Junien JL, Wettstein JG (1992) Role of opioids in peripheral analgesia. Life Sci 51:2009-2018.

Kayser V, Gobeaux D, Lombard MC, Guilbaud G, Besson JM (1990) Potent and long lasting antinociceptive effects after injection of low doses of a mu-opioid receptor agonist, fentanyl, into the brachial plexus sheath of the rat. Pain 42:215-225.

Law PY, Wu J, Koehler E, Loh HH (1985) Demonstration and characterization of opiate inhibition of the striatal adenylate cyclase activity. J Neurochem 36:1834-1846.

Law PY, Hom DS, Loh HH (1991) Effect of chronic D-Ala2. D-Leu5enkephalin or pertussis toxin treatment on the high-affinity state of delta-opioid receptor in neuroblastoma $\times$ glioma NG108-15 hybrid cells. J Pharmacol Exp Ther 256:710-716.

Levine JD, Taiwo YO (1989) Involvement of the mu-opiate receptor in peripheral analgesia. Neuroscience 32:571-575.

Mankman MH, Dvorkin B, Crain SM (1988) Modulation of adenylate cyclase activity of mouse spinal cord-ganglion explants by opioids, serotonin and pertussis toxin. Brain Res 445:303-313.

Martin HA, Basbaum AI, Kwiat GC, Goetzl EJ, Levine JD (1987) Leukotriene and prostaglandin sensitization of cutaneous high-threshold C- and A-delta mechanonociceptors in the hairy skin of rat hindlimbs. Neuroscience 22:651-659.

Mayer DJ, Price DD (1976) Central nervous system mechanisms of analgesia. Pain 2:379-404. 
Moiniche S, Dahl JR, Kehlet H (1993) Peripheral antinociceptive effects of morphine after burn injury. Acta Anaesthesiol Scand 37:710712.

Ouseph AK, Khasar SG, Levine JD (1995) Multiple second messenger systems act sequentially to mediate rolipram-induced prolongation of prostaglandin E2-induced mechanical hyperalgesia in rat. Neuroscience 64:769-776.

Parsons CG, Herz A (1990) Peripheral opioid receptors mediating antinociception in inflammation. Evidence for activation by enkephalinlike opioid peptides after cold water swim stress. J Pharmacol Exp Ther 255:795-802

Pitchford S, Levine JD (1991) Prostaglandins sensitize nociceptors in cell culture. Neurosci Lett 132:105-108

Polastron J, Boyer MJ, Quertermont Y, Thouvenot JP, Meunier JC, Jauzac $P$ (1990) Mil-opinid receptors and not kappa-opioid receptors are coupled to the adenylate cyclase in the cerebellum. J Neurochem 54:562-570

Puttfarcken PS, Werling LL, Cox BM (1988) Effects of chronic morphine exposure on opioid inhibition of adenylyl cyclase in $7315 \mathrm{c}$ cell membranes: a useful model for the study of tolerance at mu opioid receptors. Mol Pharmacol 33:520-527.

Sharma SK, Nirenberg M, Klee WA (1975) Morphine receptors as regulators of adenylate cyclase activity. Proc Natl Acad Sci USA 72: $590-594$.

Smith TW, Buchan P, Parsons DN, Wilkinson S (1982) Peripheral antinociceptive effects of N-methyl morphine. Life Sci 31:1205-1208.

Stein C (1991) Peripheral analgesic actions of opioids. J Pain Symptom Management 6:119-124.

Stein C., Millan M., Yassouridis A, Herz A (1988) Antinociceptive effects of mu- and kappa-agonists in inflammation are enhanced by a peripheral opioid receptor-specific mechanism. Eur J Pharmacol 155:255 264

Stein C, Millan MJ, Shippenberg TS, Peter K, Herz A (1989) Peripheral opioid receptors mediating antinociception in inflammation. Evidence for involvement of mu, delta and kappa receptors. J Phamacol Exp Ther 248:1269-1275
Stein C, Comisel K, Haimerl E, Yassouridis A, Lehrberger K, Herz A, Peter K (1991) Analgesic effect of intraarticular morphine after arthroscopic knee surgery. N Engl J Med 325:1123-1126.

Taiwo YO, Levine JD (1990) Direct cutaneous hyperalgesia induced by adenosine. Neuroscience 38:757-762.

Taiwo YO, Levine JD (1991) Further confirmation of the role of adenyl cyclase and of cAMP-dependent protein kinase in primary afferent hyperalgesia. Neuroscience 44:131-135.

Taiwo YO, Coderre TJ, Levine JD (1989) The contribution of training to sensitivity in the nociceptive paw-withdrawal test. Brain Res 487 : $148-151$.

Tsuchida A, Thompson R, Olsson RA, Downey JM (1994) The antiinfarct effect of an adenosine Al-selective agonist is diminished after prolonged infusion as is the cardioprotective effect of ischaemic preconditioning in rabbit heart. J Mol Cell Cardiol 26:303-311.

VanCaulker P, Muller M, Hamprecht B (1979) Adenosine regulates via two different types of receptors the accumulation of $\mathrm{CAMP}$ in cultured brain cells. J Neurochem 33:999-1005.

Vasko MR, Campbell WB, Waite KJ (1994) Prostaglandin E2 enhances bradykinin-stimulated release of neuropeptides from rat sensory neurons in culture. J Neurosci 14:7-4997.

Wang Z, Bilsky EJ, Porreca F, Sadee W (1994) Constitutive $\mu$-opioid receptor activation as a regulatory mechanism, underlying narcotic tolerance and dependence. Life Sci 54:339-350.

Wang J-F, Khasar SG, Ahlgren SC, Levine JD (1995) Sensitization of C-fibers by prostaglandin $\mathrm{E}_{2}$ in the rat is inhibited by guanosine $5^{\prime}$ O-(2-thiodiphosphate), $2^{\prime} \cdot 5^{\prime}$-dideoxyadenosine and WIPTIDE. Neuroscience, in press.

Way EL (1993) Opioid tolerance and physical dependence and their relationship. Handb Exp Pharmacol 104:573-596.

Werling LL, McMahon PN, Cox BM (1989) Selective changes in muopioid receptor properties induced by chronic morphine exposure. Proc Natl Acad Sci USA 86:6393-6397.

Wheeler-Aceto H, Cowan A (1991) Involvement of a peripheral component in the antinociceptive effects of opioids in a model of tonic pain. Nida Res Monogr 105:399-400. 